\title{
Using a continuous function for residence time to quantify the impact of climate change on the dynamics of thermally stratified lakes
}

\author{
David Glen GEORGE* and Margaret Anne HURLEY \\ The Centre for Ecology and Hydrology, The Windermere Laboratory, Far Sawrey, Ambleside, Cumbria LA22 OLP, UK \\ *e-mail corresponding author: dgg@ceh.ac.uk
}

\begin{abstract}
The residence time of a lake is usually expressed as an annual average. This takes no account of the short-term fluctuations in the rainfall which result in a pronounced seasonal variation in the effective residence time. In this paper, we describe how we combine the regional output of an established Global Climate Model (GCM) with a new definition of residence time to quantify the effect of future changes in the weather on the dynamics of thermally stratified lakes. Illustrative examples are taken from a series of lakes in the English Lake District and demonstrate that some lakes respond to changes in the rainfall that extend over two, three or even four seasons. The critical factors influencing the hydraulic responses of the selected lakes were the size of each basin and the ratio of epilimnetic to hypolimnetic volume. In the smaller lakes, the effective residence time was just a few days whilst the large lakes had residence times that were close to one year. This division of lakes into single season and multi-season lakes is functionally very important since the projected changes in the weather may well be confined to a particular time of year.
\end{abstract}

Key words: residence time, English Lake District, mathematical model, Global Climate Model

\section{INTRODUCTION}

Changes in the weather, on the scale now being suggested (Kattenberg et al. 1996), will have a major effect on the physical characteristics of lakes throughout Europe. At high latitudes and altitudes, some of the most important effects will be those associated with changes in the freeze-thaw dates of lakes (Livingstone 1997). At mid-latitudes, the physical characteristics of the lakes will be more strongly influenced by changes in the rainfall and systematic variations in the residence time of the lakes (George 2002). Lake residence time is usually expressed on an annual basis and takes no account of the seasonal variations in the rainfall. Large lakes are relatively insensitive to such short-term variations but these seasonal variations have a major effect on the flushing time of small to medium-sized lakes. In this paper, we describe a simple model that can be used to calculate the effective residence time of these lakes and then use this model to quantify the effects of future changes in the weather on the residence time of several lakes in the English Lake District. The lakes in this area cover a range of sizes and include lakes that are relatively well mixed as well as those that remain thermally stratified throughout the summer. The climate change scenarios used to drive this model have been selected from those published by the United Kingdom Climate Impacts Programme (Hulme \& Jenkins 1998). These scenarios are widely used for climate impacts studies in the UK and are based on the latest generation of Global Climate Models (GCMs) developed by the UK Meteorological Office (Johns et al. 1997).

\section{SAMPLING AND METHODS}

\subsection{The lakes of the English Lake District}

The Lake District is a mountainous area located in the north-west of England and extends from latitudes $54^{\circ}$ to $56^{\circ} \mathrm{N}$. Figure 1 shows the location of the larger lakes which were formed during the last Ice Age by glaciers flowing outwards from a central dome. Most of the lakes are sufficiently deep to remain thermally stratified during the summer but two lakes, Bassenthwaite and Derwentwater, only become thermally stratified during warm, calm periods. Table 1 lists fifteen of these lakes arranged in ascending order of their average residence time. The residence times listed are those derived by the application of the "hindcasting" model. In some cases, these differ from those quoted in the literature since the residence times in table 1 take into account both the effect of thermal stratification and the temporal and spatial variation in the average rainfall. Two large lakes, Thirlemere and Haweswater, have been excluded from this list since these are water supply reservoirs with regulated flushing regimes.

The climate of the English Lake District is mild but very wet and there are large local variations in the average rainfall. There is also a strong orographic component to the rainfall which typically ranges from a minimum of $3 \mathrm{~mm}$ per day near the coast to a maximum of $12 \mathrm{~mm}$ per day in the mountains. The key factors influencing the residence time of the lakes are their size, the area of the surrounding catchment and the timing and intensity of thermal stratification. The shortest residence times are thus recorded for Rydal Water, a small "riv- 

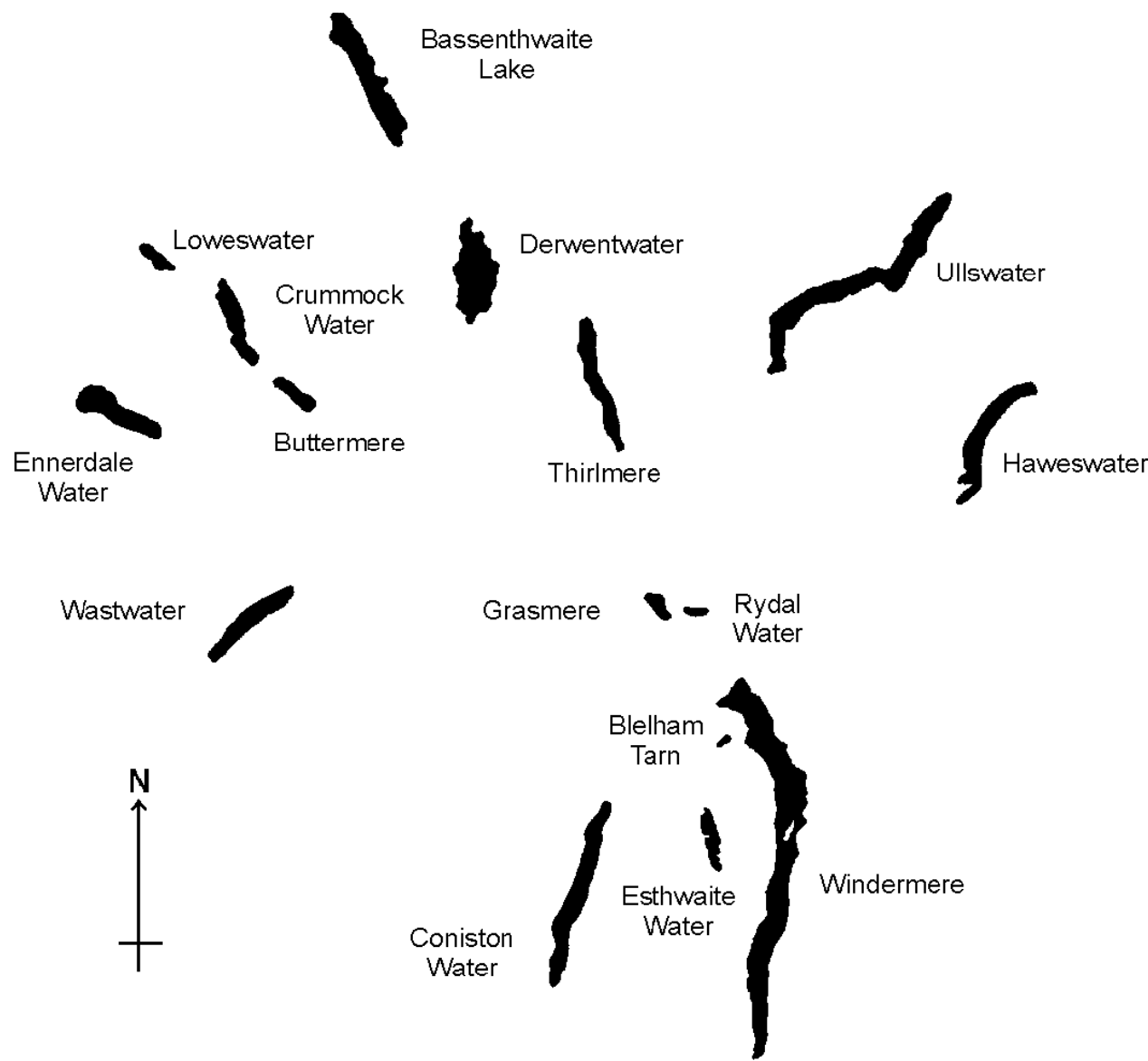

Fig. 1 Map of the English Lake District showing the position of the larger lakes.

Tab. 1. The physical characteristics of the fifteen lakes. The lakes have been arranged in ascending order of their average residence time.

\begin{tabular}{lcccc}
\hline & $\begin{array}{c}\text { Area } \\
\left(\mathrm{km}^{2}\right)\end{array}$ & $\begin{array}{c}\text { Mean depth } \\
(\mathrm{m})\end{array}$ & $\begin{array}{c}\text { Annual rainfall } \\
(\mathrm{mm})\end{array}$ & $\begin{array}{c}\text { Residence time } \\
(\text { days })\end{array}$ \\
\hline Rydal Water & 0.3 & 7.0 & 2482 & 17 \\
Bassenthwaite & 5.3 & 5.3 & 2065 & 26 \\
Grasmere & 0.6 & 7.7 & 2533 & 34 \\
Blelham Tarn & 0.1 & 6.8 & 1918 & 54 \\
Derwentwater & 5.4 & 5.5 & 2645 & 87 \\
Windermere (S) & 6.7 & 16.8 & 2196 & 94 \\
Esthwaite Water & 1.0 & 6.4 & 1912 & 111 \\
Buttermere & 0.9 & 16.6 & 2803 & 121 \\
Crummock & 2.5 & 26.7 & 2257 & 172 \\
Ennerdale & 3.0 & 17.8 & 2551 & 190 \\
Loweswater & 0.6 & 8.4 & 1614 & 208 \\
Windermere (N) & 8.1 & 25.1 & 2016 & 221 \\
Ullswater & 8.9 & 25.3 & 2166 & 300 \\
Coniston & 4.9 & 24.1 & 2226 & 349 \\
Wastwater & 2.9 & 40.2 & 2670 & 352 \\
\hline
\end{tabular}

erine" lake in the Windermere catchment and the longest residence times for Wastwater a large lake with a particularly deep thermocline.

\subsection{The meteorological and limnological data}

The meteorological data analysed here were obtained from seven weather stations distributed throughout the Lake District (British Atmospheric Data Centre web-site). Information on the hydrological characteristics of the lakes was extracted from a Flood Forecasting data-base developed by the Centre for Ecology and Hydrology, Wallingford, UK. This is a commercial product distributed on CD-ROM (FEH CD 1999) from which can be extracted topographic and hydrological information on catchments throughout the UK. Estimates of the average annual total rainfall for each catchment were 
abstracted from these records for the reference period 1961-1990. This period is recommended by the Intergovernmental Panel on Climate Change and is widely used as a "baseline" for climate impacts studies. The annual totals were then re-scaled to monthly averages using the records available from the seven weather stations. Daily rainfall was estimated by dividing these monthly totals by the number of days in the month. Estimates of the total volume of water reaching the lakes were obtained by subtracting the amount of water lost by evapotranspiration from these totals. The evapotranspiration rates were abstracted from unpublished records provided by colleagues from $\mathrm{CEH}$ Wallingford.

The temperature measurements used to define the depth of the thermocline in the selected lakes were extracted from a number of unpublished reports produced by the Freshwater Biological Association and the Institute of Freshwater Ecology. In all cases, the measurements were taken at a central station using some form of profiling instrument. In the 1970's and early 1980's these measurements were taken with a thermistor fitted to a Mackereth oxygen electrode but more recent measurements were taken with a Yellows Springs Instruments meter.

\subsection{The model for residence time}

The theoretical residence time of a lake is usually calculated by relating the annual amount of water passing through the lake to the volume of the whole basin. The effective residence time may, however, be influenced by a number of factors such as the timing of stratification, the depth of the thermocline and the variability of the inflows. In this paper, we use a simple integration model to "hindcast" the residence times of the selected lakes on a daily basis. Before and after stratification the whole lake volume was used in the model, but during stratification the volume of the epilimnion was more appropriate.

The "hindcast" residence time for each day of the year, $T$, was calculated as follows. Let $W(S)$ represent the volume of water entering the lake on each day $S, S$ $=1 \ldots 365$ and $V(T)$ be the volume of lake water to be flushed through by day $T$. If $V_{L}$ is the average lake volume and $V_{E}$ is the average epilimnetic volume then:

$$
\begin{gathered}
\quad V(T)=V_{L} \text { for days } T=1 \ldots 151, \\
V(T)=V_{E} \text { for days } T=152 \ldots 287 \\
\text { and } V(T)=V_{L} \text { for days } T=288 \ldots 365 .
\end{gathered}
$$

Thus stratification is assumed to set in within each lake on 1st June (day 152) and to break down at $14^{\text {th }}$ October (day 287). The "hindcast" residence time, $R$ days, on day $T$ is given by:

$$
\Sigma_{S=T-R}^{T} W(S)=V(T) .
$$

Thus, on average, any element of lake water (whole lake or epilimnetic volume as appropriate) resident on day $T$ would not have been previously resident on day
$T-R$. The volume of water entering the lake $W(S)$ is estimated from the annual rainfall in the catchment, $Q$, the catchment area, $A$, the percentage of annual rainfall, $P_{i}$, $(i=1 \ldots 12)$ falling in the month containing day $S$ and the evapotranspiration rate, $E_{i}$, for the same month, thus:

$$
W(S)=A\left(\left(Q P_{i} / 100\right)-E_{i}\right) / D_{i}
$$

and $D_{i}$ is the number of days in the month containing day $S$.

To compute future values for the year 2050, the monthly rainfall term $\left(Q P_{i} / 100\right)$ was adjusted by the predicted percentage change in each month and the evapotranspiration $E_{i}$ term was adjusted to the predicted future monthly level, all other quantities being kept constant. To obtain seasonal or annual values of residence time, the daily residence time was averaged over the days in the season or whole year.

\subsection{The climate change scenarios}

The precipitation scenarios used here are based on a set of Global Climate Model (GCM) experiments conducted by the UK Hadley Centre in 1995 and 1996. These experiments were conducted using a coupled ocean-atmosphere GCM called HadCM2. This model has been rigorously tested and validated and is one of the most powerful climate model currently available. A brief description of the model and the experiments used to generate the scenarios has been given in a report circulated by the UK Climate Impacts Programme (Hulme \& Jenkins 1998). Figure 2 shows the changes in the winter and summer rainfall projected by this model for a 300 by $350 \mathrm{~km}$ "box" that covers the north west of England. The baseline conditions are the winter and summer averages for the IPCC reference period 19611990 and the averages shown are those generated by four different warming scenarios for the year 2050. An outline description of these scenarios has also been included in the UKCIP report. The warming rates vary from a minimum of ca $0.1{ }^{\circ} \mathrm{C}$ per decade for the "Low" scenario to a maximum of ca $0.3{ }^{\circ} \mathrm{C}$ for the "High" scenario. All four scenarios suggest that there will be a systematic increase in the winter and summer air temperature and the winter rainfall but the more strongly forced scenarios show that there will be a marked reduction in the summer rainfall. In this paper, we use the results produced by the Medium-High scenario to generate the residence time projections for the selected lakes. This scenario provides a reasonable compromise between the two extreme rates of forcing but must still be regarded as a plausible rather than a probable projection. The only other climate variable used in our model is the projected evapotranspiration rate for the same scenario. This is assumed to remain the same for the winter period but then to increase by $6 \%$ by the summer of 2050 . 
(1)

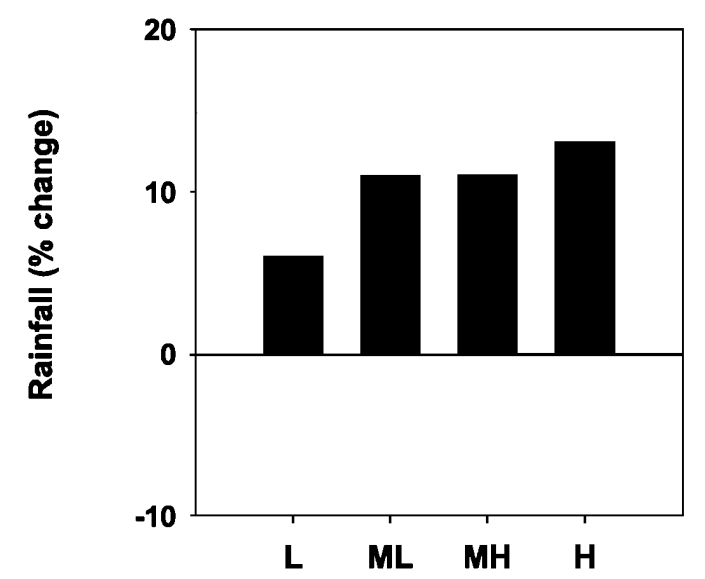

(2)

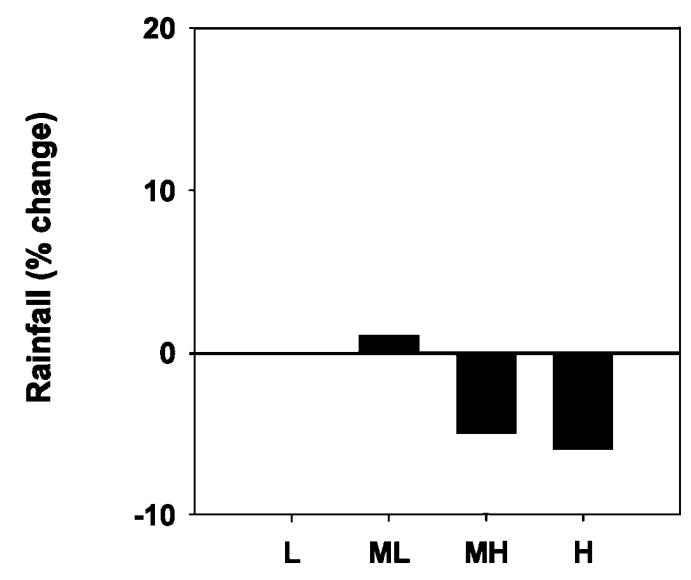

Fig. 2. Bar charts showing the percentage change in the rainfall projected for the year 2050 by the UK Meteorological Office HadCM2 Global Climate Model. The projections are for a 300 by $350 \mathrm{~km}$ "box" covering the north-west of England. The annotations show that the simulations were based on the "Low", "Medium-Low", "Medium High" and "High" scenarios of global warming.

\subsection{Downscaling the projected changes in rainfall}

Two different methods are commonly used to downscale the output of GCMs: dynamic downscaling where nested regional climate models are used to simulate subgrid features (Jones et al. 1995) and empirical downscaling where local observations are used to derive appropriate statistical relationships between the projected regional averages and the local estimates (Kim et al. 1984). In this paper, we used the empirical method to downscale the output of the GCMs to the level of the individual catchments. In each case, we used the seasonal changes suggested by the GCM to generate a series of monthly averages that were then used to re-scale the measured variations in the local rainfall.

\section{RESULTS}

The method used to "hindcast" the seasonal variation in the residence time produced a wide range of responses that reflected both the physical characteristics of the lakes and the local variations in the rainfall. In the calculations presented here, we have used the meteorological data acquired between 1961 and 1990 to characterise the "baseline" responses of the lakes and compared these with the variations projected for the year 2050. These projections will, almost certainly, change as the performance of the climate models continues to improve. The intention here is not to provide a definitive set of predictions but to demonstrate how these methods can be used to characterise the sensitivity of the lakes to future changes in the climate.

Table 2 summarises the results obtained when the model was used to simulate the effect of future changes in the weather on the residence time of the fifteen lakes. The values reported in the table are the differences (in days) between the "historical" residence time of the lakes and those projected by the GCM for 2050. In this table, positive values imply that the residence time of a particular lake will increase in 2050 whilst negative values indicate a decrease over the same period. The results show that the annual residence time for most of the lakes will decrease in the coming decades, the only exceptions being the lakes with very short residence times. The most pronounced reductions will be those estimated for the spring and the winter when the rainfall is projected to increase by at least $10 \%$. In summer, the residence time of a number of small lakes is projected to increase but the most pronounced increases are those recorded in a number of large lakes during the autumn period. The main factor responsible for these lake to lake variations is the integrating effect of the basin on the local rainfall. All the lakes with positive values in the autumn have residence times that are greater than fifty days i.e. the effect of a late summer drought can still be detected in early autumn.

A detailed analysis of the factors influencing the form of the residence time curves for the different lakes is outside the scope of this paper. Some indication of the range of dynamics identified is gained by referring to four illustrative examples. Figure 3(1) compares the results generated by the model for Bassenthwaite Lake under current and future weather conditions. Since this lake is effectively isothermal, the results shown are for the well-mixed basin. The main factor influencing the residence time of this lake is the large size of the catchment relative to the lake volume. The "historical" and "projected" curves are very similar and the only effect of global warming is a slight increase in the summer residence time. Figure 3(2) compares the results generated by the model for Ennerdale under current and future weather conditions. Ennerdale is a lake with a long 
Tab. 2. Projected seasonal and annual change (days) in residence time of the fifteen lakes. A negative change means residence time is shorter in 2050 than in the historical reference period.

\begin{tabular}{lccccc}
\hline Lake & Spring & Summer & Autumn & Winter & Annual \\
\hline Rydal Water & -1.6 & 3.2 & -0.8 & -1.2 & -0.1 \\
Bassenthwaite & -1.8 & 7.4 & -0.3 & -1.2 & 1.1 \\
Grasmere & -2.2 & 5.3 & -0.7 & -2.1 & 0.1 \\
Blelham Tarn & -2.9 & 6.3 & 2.0 & -2.6 & 0.7 \\
Derwentwater & -4.9 & -0.8 & 2.3 & -4.7 & -2.0 \\
Windermere (S) & -6.3 & -0.0 & 4.8 & -5.7 & -1.8 \\
Esthwaite Water & -6.4 & -1.8 & 6.1 & -5.7 & -1.9 \\
Buttermere & -8.8 & -2.1 & 3.4 & -7.6 & -3.8 \\
Crummock & -12.6 & -1.5 & 3.6 & -12.8 & -5.8 \\
Ennerdale & -12.7 & -4.7 & -0.3 & -13.0 & -7.7 \\
Loweswater & -12.6 & -6.8 & -1.5 & -12.0 & -8.2 \\
Windermere (N) & -17.8 & -3.5 & -2.3 & -20.4 & -11.0 \\
Ullswater & -50.3 & -5.6 & -7.1 & -13.2 & -19.1 \\
Coniston & -17.8 & -7.6 & -11.9 & -15.7 & -13.2 \\
Wastwater & -20.7 & -5.7 & -10.5 & -17.5 & -13.6 \\
\hline
\end{tabular}

(1)

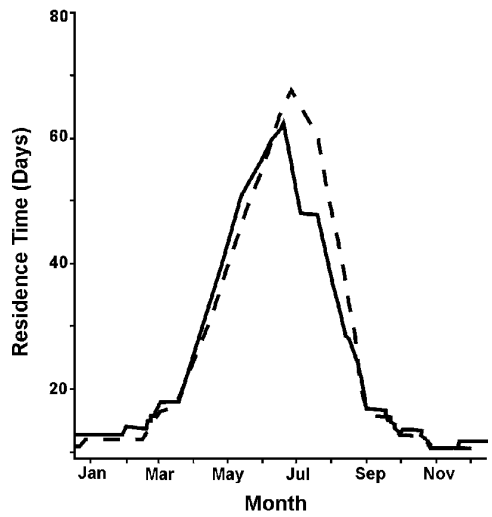

(3)

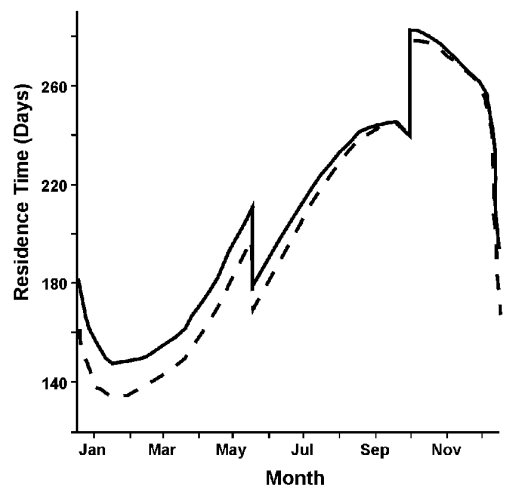

(2)

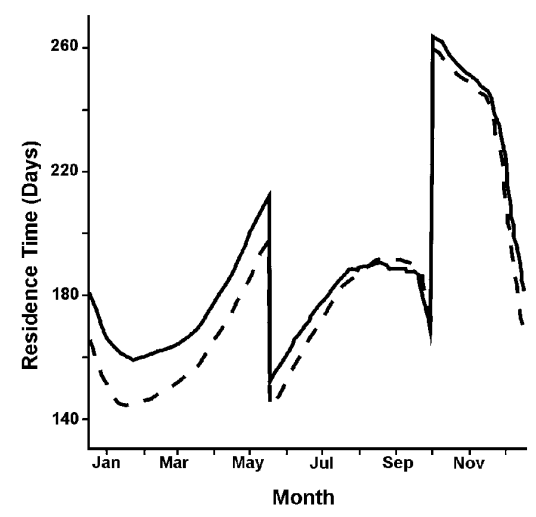

(4)

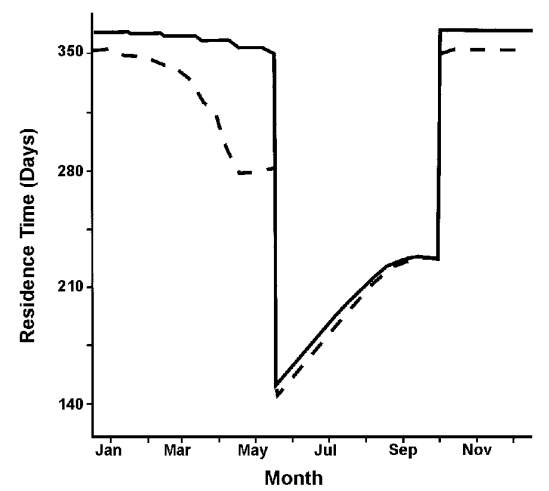

Fig. 3. Hindcast residence time curves for (1) Bassenthwaite Lake, (2) Ennerdale, (3) Loweswater and (4) Ullswater under current (solid line) and future (broken line) weather conditions.

residence time and a relatively deep seasonal thermocline. The "historical" and "projected" curves are very similar and the main effect of global warming is a slight reduction in the residence time in the first half of the year. Figure 3(3) compares the results generated by the model for Loweswater under current and future weather conditions. Loweswater is a lake with a relatively long residence time but the seasonal thermocline is deep and stratification has little effect on the annual flushing rate. The "historical" and "projected" curves for Loweswater are again very similar with the effects of global warming being most pronounced very early in the year. Fig- 
ure 3(4) compares the results generated by the model for Ullswater under current and future weather conditions. Ullswater is a lake with a long residence time where the recharge time for the whole basin is very close to one year. The "historical" and "projected" curves for Ullswater differ significantly over the spring period and show the extent to which this large lake is influenced by the 'lagged' effect of the winter increase in the rainfall.

\section{DISCUSSION}

In the smaller lakes of the English Lake District, year-to-year variations in the residence time can have a major effect on their seasonal dynamics. For example, variations in the winter rainfall have been shown to influence the flux of phosphorus into Blelham Tarn (George 2002) and the winter biomass of phytoplankton in Esthwaite Water and Blelham Tarn (Talling 1993). In this paper we have used a simple "hindcasting" model to estimate the seasonal variation in the residence time of all the large "natural" lakes in the English Lake District. The examples presented show how the method can be used to characterise the effect of both current and future changes in the weather and identify the times in the year when the lakes are most responsive to changes in the rainfall. The most striking feature of these simulations is the range of dynamic responses identified in the different lakes. In the case of the smaller lakes, the flushing effects are quite rapid i.e. the lakes respond to the variations in the rainfall recorded over several weeks or even days. In the case, of the larger lakes the flushing effects can be quite prolonged i.e. the lakes may integrate the effect of changes in the rainfall over several months or even a year. This division of lakes into single season and multi-season lakes is functionally very important since, in future, periods of very dry or very wet weather may well be confined to just a few weeks in the year.

In this paper, we have used long-term averages to compare the flushing characteristics of the different lakes. The model described can, however, be adapted for a number of other "weather-related" applications e.g. to quantify the effect of extreme year-to-year variations in the weather on the residence time of a particular lake. In this instance, the model could either by driven by rainfall measurements acquired in two contrasting years or ensembles of years chosen to represent the "driest" and "wettest" periods.

The mathematical definition of residence time given here we describe as "hindcast" residence time. This measures how many days we must go back in time, on average, so that today's lake water is different to that previously resident in the lake. This is useful for a number of applications such as modelling of algal popula- tions or the seasonal change in the nutrient status of a lake. However, equally well, we could have defined the "forecast" residence time which is the number of days from now that we must go in the future so that today's lake water will be totally refreshed. This definition has application in pollution impact studies where we wish to know how long it would take for a pollutant to be flushed through the lake system. The "forecast" and "hindcast" residence times are dissimilar and, in any application, care must be taken to select the most appropriate measure.

\section{ACKNOWLEDGEMENTS}

We would like to thank Diane Hewitt for processing rainfall records from the British Atmospheric Data Centre for permission to use archived data. This study was part-funded by the UE CLIME project (EVK1-CT2002-00121.

\section{REFERENCES}

FEH CD-ROM. 1999. Version 1.0. Flood Estimation Software. Centre for Ecology and Hydrology, Institute of Hydrology, Wallingford, UK.

George, D.G. 2002. Regional-scale Influences on the Longterm Dynamics of Lake Plankton. In: P.J.le B. Williams, D.N. Thomas \& C.S. Reynolds (Eds), Phytoplankton Productivity: Carbon assimilation in marine and freshwater ecosystems. Blackwell Science, Oxford: 265-290.

Hulme, M. \& G.J. Jenkins. 1998. Climate change scenarios for the UK: scientific report UKCIP Technical Report No.1. Climatic Research Unit, Norwich: 80 pp.

Johns, T.C., R.E. Carnell, J.F. Crossley, J.M. Gregory, J.F.B. Mitchell, C.A. Senior, S.F.B. Tett \& R.A. Wood. 1997. The second Hadley Centre coupled ocean-atmosphere GCM: model description, spinup and validation. Climate Dynamics, 13: 103-134.

Jones, R.G., J.M. Murphy \& M. Noguer. 1995. Simulation of climate change over Europe using a nested regional-climate model. I: Assessment of control climate, including sensitivity to location of lateral boundaries. $Q$. Jl R.. met. Soc., 121: 1413-1449.

Kattenburg, A., F. Giorgi, H. Grassl, G.A. Meehl, J.F.B. Mitchell, R.J. Stouffer, T. Tokioka, A.J. Weaver \& T.M.L. Wigley. 1996. Climate models - projections of future climate. In: Houghton, J.T., Meiro Filho, L.G., Callendar, B.A.., Harris, N., Kattenberg, A. \& Maskell, K. (Eds). Climate Change 1995: The Science of Climate Change. Cambridge University Press, Cambridge: 285-358.

Kim, J-W., J.T. Chang, N.L. Baker, D.S. Wilks \& W.L. Gates. 1984. The statistical problem of climate inversion: determination of the relationship between local and large-scale climate. Mon. Weath. Rev., 112: 2069-2077.

Livingstone, D.M. 1997. Break-up dates of alpine lakes as proxy data for local and regional mean surface air temperatures. Climat. Change, 37: 407-439.

Talling, J.F. 1993. Comparative seasonal changes and interannual variability and stability in a 26-year record of total phytoplankton biomass in four English lake basins. Hydrobiologia, 268: 65-98. 